\title{
An assessment of human-computer interaction research in management information systems: topics and methods
}

\author{
Ping Zhang*, Na Li
}

School of Information Studies, Syracuse University, Syracuse, NY 13244, USA

\begin{abstract}
As an emerging subfield of Management Information Systems (MIS), Human-Computer Interaction (HCI) or Human Factors studies in MIS are concerned with the ways humans interact with information, technologies, and tasks, especially in business, managerial, organizational, and cultural contexts. To date, few studies have either synthesized existing studies or drawn an overview picture of the HCI subfield in MIS. This paper first provides a framework of broad HCI issues and concerns. It then reports an assessment of a sample of published HCI articles in two top MIS journals, MIS Quarterly and Information Systems Research, over a period of thirteen years (1990-2002). It identifies the main topics studied, the main research approaches utilized, the research publication patterns, and the needs for future research efforts in this subfield. The results should be of interest to researchers in this subfield, in the MIS field, and in other related disciplines for future research, collaboration, and publication.
\end{abstract}

(C) 2003 Elsevier Ltd. All rights reserved.

Keywords: Human-computer interaction (HCI); Human factors in information systems (HFIS); Literature analysis; Literature assessment; Research methods

\section{Introduction}

Research that synthesizes existing studies to provide an overview of an emerging field is often scarce but extremely important to advance our understanding of the current status and suggest future directions of the field. This situation is especially pressing for an emerging subfield that is an overlapping or intersection of the two important disciplines, human-computer interaction (HCI) and management information systems (MIS).

* Corresponding author. Tel.: + 1-315-443-5617; fax: + 1-315-443-5806.

E-mail address: pzhang@syr.edu (P. Zhang). 
As rightly recognized by Hewett and colleagues (Hewett et al., 1992), there is no agreed upon definition of the range of topics that form the area of HumanComputer Interaction. In an attempt to derive and develop educational materials, these scholars defined HCI as "a discipline concerned with the design, evaluation and implementation of interactive computing systems for human use and with the study of major phenomena surrounding them" (Hewett et al., 1992). It is widely recognized as an interdisciplinary field where many traditional disciplines contribute to the study of its main issues (Preece, Rogers, Sharp, Benyon, Holland, \& Carey, 1994).

Management information systems (MIS) is a community of scholars interested in the development, use, and impact of information technology and systems in social and organizational settings (Zhang \& Dillon, 2003). MIS has been through a steady shift from what was a techno-centric focus to a better-balanced technology/organizational/management/social focus (Baskerville \& Myers, 2002). User attitudes, perceptions, acceptance and use of IT have been a long standing issue and a major theme of MIS since early days in computing (Lucas, 1975; Swanson, 1974).

Human-computer interaction (HCI) or Human Factors studies in MIS are "concerned with the ways humans interact with information, technologies, and tasks, especially in business, managerial, organizational, and cultural contexts" (Zhang, Benbasat, Carey, Davis, Galletta, \& Strong, 2002, p. 334). The emphases have been on both the "design, evaluation and implementation" aspect and the "use and impact in social and organizational settings" aspect of information technology for human use. Since the 1970s, MIS researchers have published abundant studies concerning HCI issues in many MIS journals. The active HCI-centered minitracks, sessions and workshops in major MIS conferences, along with the newly formed AIS Special Interest Group on HCI, have also shown high interests in HCI among MIS researchers in recent years.

With the fast development and deployment of information systems, information technology and communication technology (in this paper, we use IS or IT to represent them all) into every part of our lives, HCI issues become persuasive and fundamental. They also prompt a need to re-examine what HCI is about and how to conduct research in this area.

Several studies have been conducted to systematically assess the intellectual evolution of the MIS field in terms of its theories, topics, research methods, etc. (Alavi \& Carlson, 1992; Culnan, 1987). However, very few studies have drawn an overview picture of the HCI subfield up to date (Zhang et al., 2002). The purpose of this study is to reflect on the current status of the subfield in terms of research topics and research methods, to identify gaps that need to be addressed, and to point out future research directions.

Specifically, this paper will first depict a new framework of HCI issues, which is intended to capture the dynamics and richness of the interaction between human and technology. Utilizing the new framework for subject topics and an existing framework for research methods, the paper then reports an assessment of a limited collection of the published HCI articles from two main MIS journals, Management Information Systems Quarterly and Information Systems Research, on the following 
aspects: (1) the research topics being studied, (2) the research methods being utilized, and (3) the publication patterns of the HCI type research in the two journals over time. From the findings, we identify and discuss areas of need for future research.

The results of this study can provide useful information to scholars and practitioners in the MIS and the traditional HCI fields for future research, collaboration, publication, and practice. They can also be helpful for interested doctoral students to identify potential research topics as dissertation research.

The rest of the paper is organized as the following. Section 2 introduces a framework of broad HCI issues. Section 3 explains the methodology used in this paper for assessing the published articles. Section 4 presents the assessment results. Section 5 discusses and concludes the paper.

\section{A framework of broad HCI issues}

Only a few comprehensive frameworks of HCI issues and topics have been developed so far. This coincides with the observation that no agreed upon definitions of the range of topics for HCI exist (Hewett et al., 1992). Among these few frameworks, Eason (1991) proposed a three-level model of HCI model, as depicted in Fig. 1 .

In Fig. 1, Level 1 considers human-computer interaction as a form of conversation between two participants capable of processing information. Level 2 broadens the framework to examine user, task, and environmental factors which may affect task performance. The next level considers the factors which are important when human-computer interaction takes place within a socio-technical systems framework (Eason, 1991, p. 722). In Eason's framework, environmental factors at Level 2 mainly refer to the physical environment such as visual display terminals and physical settings in which computers are used. At Level 3, IT and the interaction

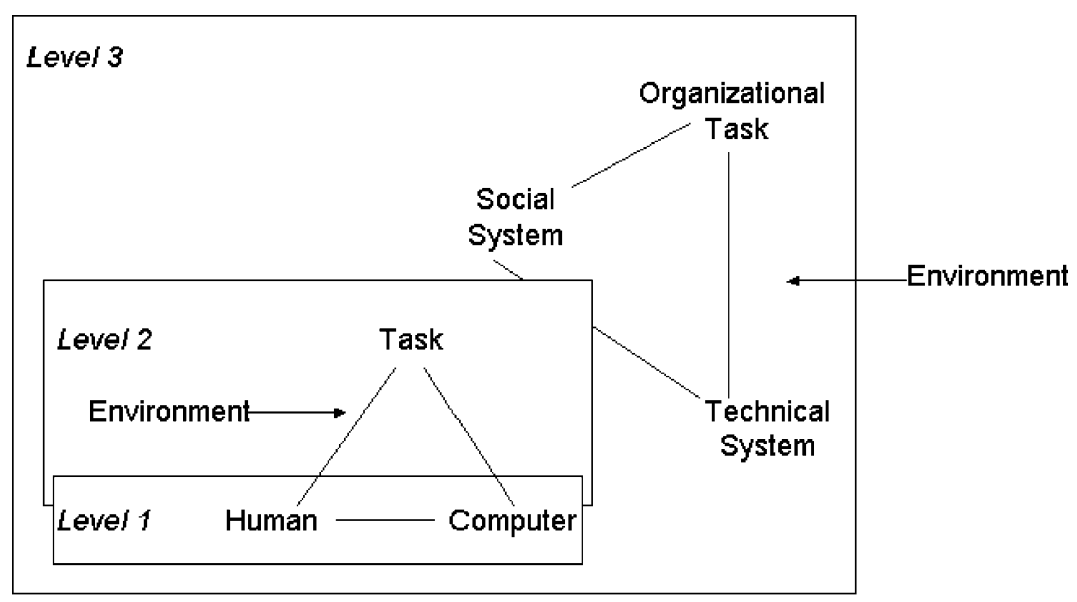

Fig. 1. A three-level model of HCI (Eason, 1991). 
between human and computers have impacts on social life by changing the nature of jobs, the way organizations operate, and the way people interact with each other. How human-computer interaction related to the society and organizations is not predetermined. Instead, it is shaped by the way the IT is designed and implemented. We think this multi-level model captures the importance of contexts of HCI concerns in real world settings. Much emphasis of the human, however, is on cognitive ergonomics.

Preece and colleagues (Preece et al., 1994) outlined the components of HCI, as seen in Fig. 2. The factors in HCI range from system constraints, system functionalities, productivity factors, to task factors, user interface, health and safety factors, comfort factors, the user, and organizational and environmental factors. The model is quite comprehensive in identifying all factors that contribute to HCI design. It also recognizes the user as a complex being with cognitive processes and capabilities but also with motivation, enjoyment, satisfaction, personality, and experience.

From an education perspective, Hewett and colleagues (Hewett et al., 1992, p. 16) proposed a framework (Fig. 3) that was intended to identify and tie together the building blocks of HCI curricula for Computer Science students with a HCI concentration or major.

\begin{tabular}{|c|c|c|c|}
\hline \multicolumn{2}{|c|}{$\begin{array}{l}\text { ORGANIZATIONAL FACTORS } \\
\text { Training, job design, politics, } \\
\text { roles, work organization }\end{array}$} & \multicolumn{2}{|c|}{$\begin{array}{l}\text { ENVIRONMENTAL FACTORS } \\
\text { Noise, heating, lighting, } \\
\text { ventilation }\end{array}$} \\
\hline $\begin{array}{c}\text { HEALTH } \\
\text { AND SAFETY } \\
\text { FACTORS } \\
\text { Stress, } \\
\text { headaches, } \\
\text { musculo-skeletal } \\
\text { disorders }\end{array}$ & $\begin{array}{r}\text { Cognitive proce } \\
\text { TH } \\
\text { Mc } \\
\text { en } \\
\text { sat } \\
\text { pe } \\
\text { exper }\end{array}$ & $\begin{array}{l}\text { s and capabilities } \\
\text { ISER } \\
\text { ation, } \\
\text { nent, } \\
\text { ction, } \\
\text { lality, } \\
\text { ce level }\end{array}$ & $\begin{array}{l}\text { COMFORT } \\
\text { FACTORS } \\
\text { Seating, } \\
\text { equipment } \\
\text { layout }\end{array}$ \\
\hline \multicolumn{4}{|c|}{$\begin{array}{c}\text { USER INTERFACE } \\
\text { Input devices, output displays, dialogue structures, } \\
\text { use of colour, icons, commands, graphics, natural language, } \\
3-D, \text { user support materials, multi-media }\end{array}$} \\
\hline \multicolumn{4}{|c|}{$\begin{array}{c}\text { TASK FACTORS } \\
\text { Easy, complex, novel, task allocation, repetitive, } \\
\text { monitoring, skills, components }\end{array}$} \\
\hline \multicolumn{4}{|c|}{$\begin{array}{c}\text { CONSTRAINTS } \\
\text { Cost, timescales, budgets, staff, equipment, building structure }\end{array}$} \\
\hline \multicolumn{4}{|c|}{$\begin{array}{l}\text { SYSTEM FUNCTIONALITY } \\
\text { Hardware, software, application }\end{array}$} \\
\hline \multicolumn{4}{|c|}{$\begin{array}{c}\text { PRODUCTIVITY FACTORS } \\
\text { Increase output, increase quality, decrease costs, decrease errors, } \\
\text { decrease labour requirements, decrease production time, } \\
\text { increase creative and innovative ideas leading to new products }\end{array}$} \\
\hline
\end{tabular}

Fig. 2. Factors in HCI (Preece et al., 1994). 


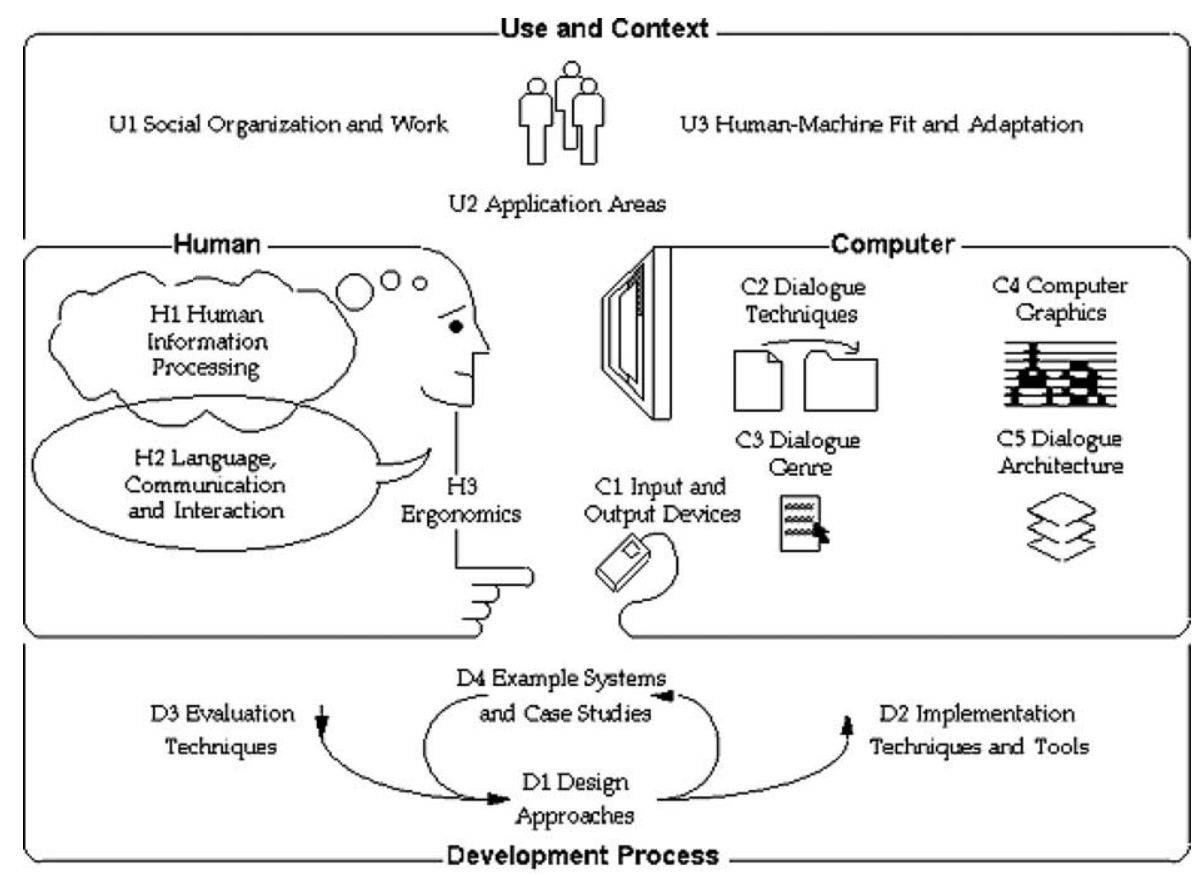

Fig. 3. ACM SIGCHI curricula for HCI (Hewett et al., 1992).

The framework identifies the need to understand humans in terms of human information processing, ergonomics, and language and communication. It also includes use and context by outlining social organization and work, and humanmachine fit and adaptation. The emphases of the framework are computer techniques for designing various system elements (devices, graphics, dialogs) for humans to interact with, and the approach and process to design, evaluate and implement interactive systems. This focus is inherent given that the framework was proposed by the ACM Special Interest Group on Computer-Human Interaction (SIGCHI).

The above frameworks have all contributed to our understanding of the possible topics in HCI. Yet, in order to understand the intersection or interaction of the two disciplines (HCI and MIS) and the broad issues studied in the intersection, a new framework is in need. This framework should be relatively parsimonious, thus easy to use. It should demonstrate the major components and their relationships, the dynamic and rich nature of HCI, and the contextual factors that play an important role in HCI. Fig. 4 is our attempt for such a framework of an overview of the broad $\mathrm{HCI}$ issues and concerns.

The first basic component is Human. There can be different ways of understanding humans in general and their specific characteristics pertinent to their interaction with IT. One way of examining the human is as depicted in Fig. 4, where four categories of issues can be explored: (1) demographics that are found in many HCI studies; (2) physical or motor skills, as those investigated in traditional 


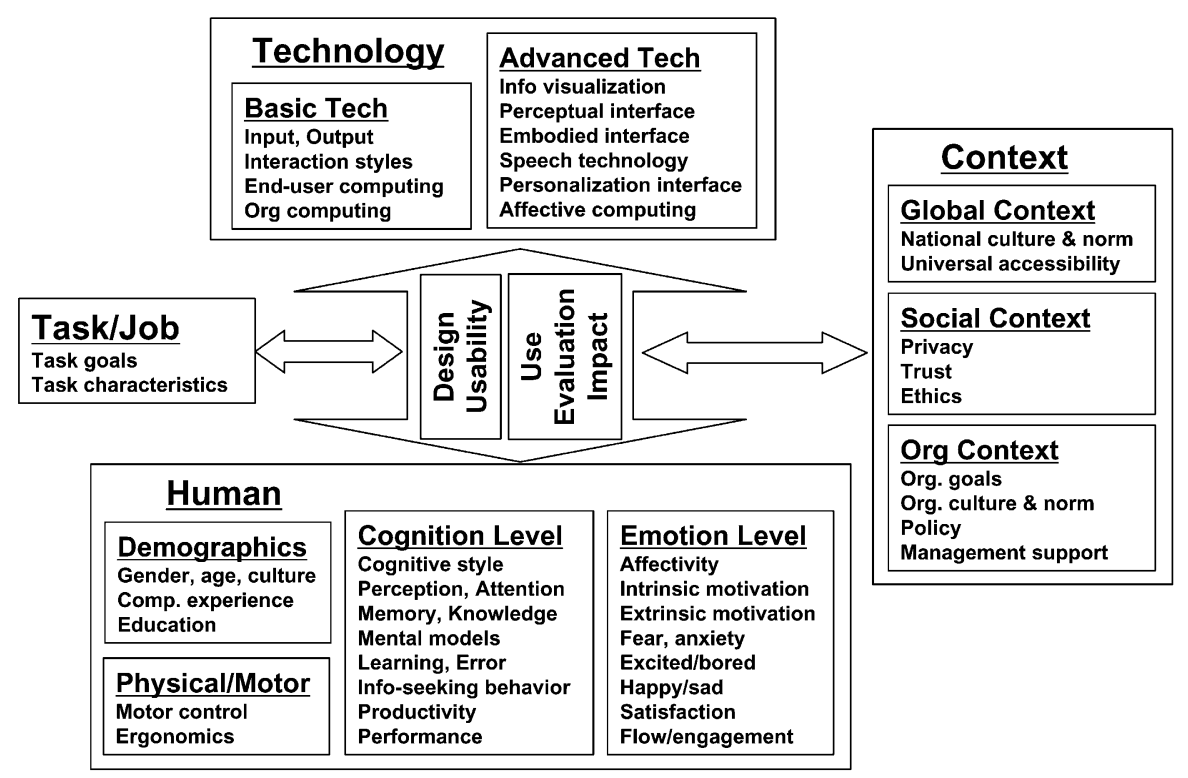

Fig. 4. A framework of broad HCI issues and concerns.

Ergonomics; (3) cognitive issues that have been examined by many HCI researchers in a good number of disciplines; and (4) emotion or affect aspect, which has started to gain attention from HCI researchers recently. The second component is the technology, broadly defined as including hardware, software, applications, data, information, knowledge, and supporting personnel and procedures. Fig. 4 indicates one way of examining technological issues when studying HCI. All the topics in Fig. 4 are meant to be illustrative, rather than exhaustive.

The thick vertical Interaction arrow (the "I" arrow) between Human and Technology represents the "I" in the HCI. It is the core or the center of all the actions. Traditionally, HCI studies were concerned with designing and implementing interactive systems for specified users, and the usability issues during the development process. The box "Design/Usability" on the left side inside the "I" arrow indicates this emphasis. A big chunk of existing HCI studies in the traditional HCI literature fits in this box. Its primary focus has been the issues prior to technology release and actual use. Ideally, concerns from both human and technology should influence design and usability issues. Thus the labeling is meant to be bi-directional.

We argue that this view of HCI centered on design and usability is narrow and limited. It misses the other half of the cycle that has a significant impact on this first half and the entire interaction experience a human has. John Carroll and colleagues, more than a decade ago, illustrated the task-artifact cycle by stating that a task sets requirements for the development of artifacts, and the use of an artifact often redefines the task for which the artifact was originally developed (Carroll, Kellogg, \& Rosson, 1991). This cycle idea supports the evolutionary view of examining HCI 
design and usability, which is depicted in the box on the right side inside the "I" arrow, "Use/Evaluation/Impact" in Fig. 4. This second half of the Interaction is concerned with the actual use of technology by users in real contexts, their evaluation of the technology, and the impact of such use and evaluation. It is important to note that design and usability studies should be informed by what we have learned from the use, evaluation and impact of the same or similar technologies. Thus the latter has implications for the former. Historically, this half has been the focal concern for the MIS field, along with organizational psychology, social psychology and social science. In the MIS field, studies on individual reactions to technology (Compeau, Higgins, \& Huff, 1999), IS evaluation from both individual and organizational levels (Goodhue, 1997, 1998; Goodhue \& Thompson, 1995), and user technology acceptance (Davis, 1989; Venkatesh \& Davis, 2000) all fall in this area.

The picture with Human, Technology, and Interaction alone is still incomplete. Nothing happens in a vacuum. The interaction experience is relevant and important only when humans use technologies to support their primary tasks within certain contexts, being organizational, social or societal. Normally, humans use technologies not for the sake of technologies but for supporting their primary tasks, being job related or entertainment oriented. In addition, tasks are carried out in a certain setting or context that imposes constraints or significance for doing and completing the tasks. Three contexts are identified: organizational context, social context, and global context. The task and context boxes add the dynamic and essential meanings to the interaction experience the human has with technology. In this sense, studies on interaction are moderated by tasks and contexts. The two horizontal arrows connecting with Task and Contexts represent this fact.

\section{Methodology}

\subsection{Article selection}

Published research articles need to be selected in order for the authors to identify research topics being studied, research methods being utilized, and publication patterns of the HCI studies in MIS. Owing to the exploratory nature of this study, two MIS journals for a thirteen year period of 1990-2002 were considered as the sources of the articles for analysis: Management Information Systems Quarterly (MISQ) and Information Systems Research (ISR). Only articles on research and education are considered for the analysis. Thus the pool of candidate articles excludes editorial introductions, editorial notes, executive summaries, or announcements.

Each paper in the pool was initially screened for HCI relevance by the criterion that the paper should address one or more aspects that fit the HCI framework outlined in Fig. 4. A paper is excluded if (1) it is concerned with group support systems or group decision support systems but does not approach it from human aspects either at the individual or collaborative level; (2) it is about pure system design or development methods or processes without linking to user's considerations; or (3) it is concerned with the personnel or human resource management aspect of human 
factors issues related to IT. This initial screening yielded a total of 171 articles. Each paper was then coded according to the schemes to be explained below. During the coding process, each paper was evaluated again for its relevance. As a result, 20 papers were excluded and 151 were considered for the final analysis.

\subsection{Classification schemes}

Each of the selected articles was classified and coded in two ways: by research topic according to the HCI framework proposed in Section 2, shown as Fig. 4, and by research method or type according to Alavi and Carlson's research type framework (Alavi \& Carlson, 1992). The latter was modified slightly to reflect the paper collection in this study.

\subsubsection{Topic}

In the MIS field, there are several attempts in providing a classification of topical subjects of studies. Culnan, for example, identified several research streams of MIS research by examining MIS publications during the period of 1980-1985 (Culnan, 1987). Barki and colleagues developed the MIS keyword classification scheme by examining the keywords in published MIS research literature (Barki, Rivard, \& Talbot, 1988, 1993). Despite the influence and wide use of these classifications, we note two limitations of using them for this study. First, they are intended to classify the entire MIS field, not for a single subfield. Second, they were developed more than a decade ago and have not been updated lately to reflect the development of the fields and changes of research foci.

In this paper, we classify HCI studies according to the broad HCI issues depicted by Fig. 4. Specifically, at a higher level, we classify an article by whether it is about issues or concerns that occur at the design/usability stage where the technology/ artifact is still "in house", or whether it is concerned with issues that occur after the technology/artifact is released and in use in a certain context. Inside each category, we further divide the topics into different aspects. In addition, we identify several articles that are concerned with the general research issues such as methodology and measurement issues, in this subfield. Thus we include this type (also considering articles dealing with teaching or education aspect of this subfield) into the third broad category. Table 1 represents the topic classification scheme developed and used in this paper. It was initially pre-tested by a set of 34 papers and evolved and refined during the rest of the coding process.

\subsubsection{Type/method}

Alavi and Carlson's research type framework (Alavi \& Carlson, 1992) is employed in this study owing to its comprehensiveness and wide acceptance in the MIS community (Pervan, 1998; Romano \& Fjermestad, 2001). Fig. 5 depicts the framework.

At the highest level, the framework distinguishes between empirical and nonempirical articles. The empirical articles capture the essence of research by relying on observation and are further divided into those that describe objects and those that describe events or processes. Nonempirical articles are those that are primarily based 
Table 1

Research topic scheme

ID Category Description and examples

A IS/IT development

A07

IS/IT use,

evaluation, impact

\section{B}

Development methods and tools

User analyst involvement

Software/hardware development

Software/hardware evaluation

User interface design \& developmen User interface evaluation

User training
Behavior
Concerned with issues that occur at the stage

of IS/IT development and relevant with the

relationship between human and technology.

Focus on the process where IS/IT is developed.

The artifact is still "in house" and being worked

on before release.

Structured approaches, Object-oriented approaches, CASE

tools, Social-cognitive approaches for developing IS/IT

User involvement, User participation, User-analyst difference,

User-analyst interaction

Programmer/analyst cognition studies, Design and development of specific or general applications or devices

System effectiveness, System efficiency, System quality, Information quality, System reliability, System flexibility

Interface metaphors, Information presentations, Multimedia

Instrumental usability (e.g. ease of use, low error rate, ease of

learning, retention rate, satisfaction), Accessibility, Information

presentation evaluation

User training issues or studies during IS/IT development (prior

product release and use)

Concerned with issues that occur when humans

use and/or evaluate IS/IT; issues related to the

reciprocal influences between IS/IT and humans.

The artifact is released and in use in real context.

Theory of Reasoned Action, Theory of Planed Behavior, Social

Cognition Theory, Self-Efficacy, Perception, Belief (expectation),

Intention, Behavior, Acceptance, Adoption, Resistance, Continue, Use 


\begin{tabular}{|c|c|c|c|}
\hline ID & Category & Description and examples & \\
\hline & B02 & Attitude & Attitude, Satisfaction, Preference \\
\hline & B03 & Learning & $\begin{array}{l}\text { Learning models, Learning processes, Training in general (different } \\
\text { from user training as part of system development) }\end{array}$ \\
\hline & B04 & Motivation & Motivation (intrinsic, extrinsic), Expectancy, Incentives \\
\hline & B05 & Emotion & Emotion, Affect, Hedonic quality, Flow, Enjoyment \\
\hline & B06 & Performance & Performance, Productivity, Effectiveness, Efficiency \\
\hline & B07 & Trust & Trust, Risk, Loyalty, Security, Privacy \\
\hline & B08 & Ethics & Ethical belief, Ethical behavior, Ethics \\
\hline & B09 & Individual differences & $\begin{array}{l}\text { Personality, Trait, Cognitive style (e.g. visual vs. verbal oriented, } \\
\text { field dependent/independent), Locus of control, Learning style }\end{array}$ \\
\hline & B10 & Individual demographics & $\begin{array}{l}\text { Age, Gender, Education, Cultural background, Experience, } \\
\text { Knowledge }\end{array}$ \\
\hline & B11 & Interpersonal relationship & $\begin{array}{l}\text { Conflict, Interdependence, Agreement/Disagreement, Interference, } \\
\text { Tension, Leadership, Influence }\end{array}$ \\
\hline & B12 & User support & $\begin{array}{l}\text { Issues related to information center, end-user computing support, } \\
\text { general user support }\end{array}$ \\
\hline \multirow[t]{3}{*}{$\mathrm{C}$} & Research \& education & & Address research and education issues/concerns \\
\hline & $\mathrm{C} 01$ & Research & \\
\hline & $\mathrm{C} 02$ & Education & \\
\hline
\end{tabular}


on ideas, frameworks, and speculations rather than on systematic observation. The three italic types under empirical for events/processes in Fig. 5 are modifications to Alavi and Carlson's original framework: the original "case study" is divided into "positivist case study" and "interpretive case study." Individual-based "Interview" is added to the framework. Table 2 provides the descriptions and examples for the detailed research types reflected in this study.

\subsection{Procedure}

Two researchers independently evaluated and coded an initial set of 34 papers to refine the topic framework and to get familiar with the coding process. All disagreements were discussed and resolved. Then, each of the remaining articles was evaluated for relevance and coded according to the two classification schemes by the two researchers independently. A coding worksheet was developed in Excel to record coding results and explanations when necessary. An article may have multiple subject topics as the essential inquiries proposed by the authors. Only the main topics of the paper were considered when assigning codes for subject topics. The number of topics per article ranged from one to six with a mean of 2.05 and a standard deviation of 1.06. A paper could also be assigned more than one research

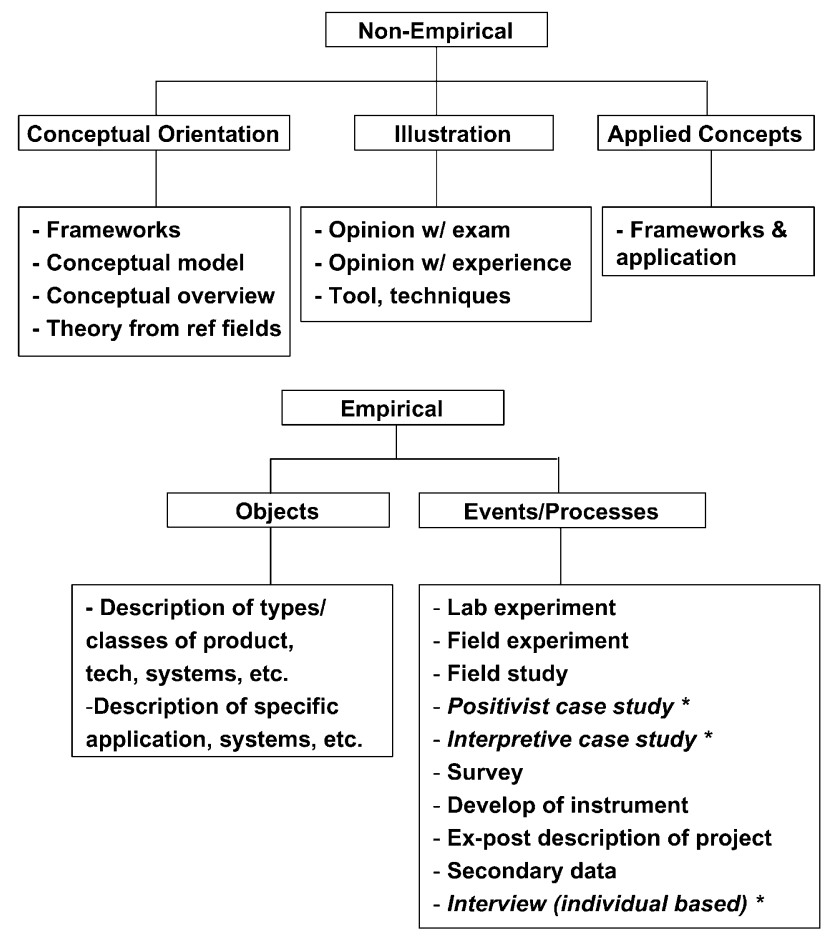

Fig. 5. Research type framework. *Modifications to Alavi \& Carlson's original work. 
Table 2

Research type scheme and examples

\begin{tabular}{|c|c|c|c|c|}
\hline & ID & Category name and description & Example 1 & Example 2 \\
\hline $\begin{array}{l}1 \\
1.1\end{array}$ & $\begin{array}{l}\text { Non-Empirical } \\
\text { Conceptual } \\
\text { Orientation }\end{array}$ & & & \\
\hline 1.1 .1 & & $\begin{array}{l}\text { Frameworks: Proposes a framework } \\
\text { for defining the content and scope } \\
\text { of HCI in MIS context, and provides } \\
\text { directions. }\end{array}$ & None & \\
\hline 1.1 .2 & & $\begin{array}{l}\text { Conceptual model of a process or } \\
\text { structure: presents an integrated, } \\
\text { schematic representation of a HCI-related } \\
\text { process, structure, behavior, activity, } \\
\text { organization, method, etc. }\end{array}$ & $\begin{array}{l}\text { George, J. F. (1996). } \\
\text { Computer-Based Monitoring: } \\
\text { Common Perceptions and } \\
\text { Empirical Results. MIS Quarterly, } \\
\text { 20(4), 459-480. }\end{array}$ & $\begin{array}{l}\text { Orlikowski, W. J., \& Iacono, } \\
\text { C. S. (2001). Research } \\
\text { Commentary: Desperately } \\
\text { Seeking the IT in IT } \\
\text { Research-A Call to } \\
\text { theorizing the IT Artifact. } \\
\text { Information Systems } \\
\text { Research, 12(2), 121-134. }\end{array}$ \\
\hline 1.1 .3 & & $\begin{array}{l}\text { Conceptual overviews of ideas, theories, } \\
\text { concepts, etc.: contains an overview of } \\
\text { many concepts or theories in one or } \\
\text { more areas, and does not propound or } \\
\text { support any individual theory, idea, } \\
\text { or approach. }\end{array}$ & $\begin{array}{l}\text { Gerlach, J. H., \& Kuo, F.-Y. (1991). } \\
\text { Understanding Human Computer } \\
\text { Interaction for Information } \\
\text { Systems Design. MIS Quarterly, } \\
\text { 15(4), } \\
527-550 .\end{array}$ & \\
\hline 1.1.4 & & $\begin{array}{l}\text { Theory from reference disciplines: presents } \\
\text { theory or theories drawn from outside the } \\
\text { HCI sub-field but applied within an }\end{array}$ & None & \\
\hline
\end{tabular}


Table 2 (continued)

\begin{tabular}{llcl}
\hline ID & Category name and description & Example 2
\end{tabular}

1.2 Illustrative

1.3 Applied Concepts
Opinion (pure, or supported by examples): gives advice and guidance for practice, in the form of rules and recommendations, steps or procedures to be followed, hints and warnings, etc. May be supported by examples and applications.

Opinion (supported by personal experiences): None as for 1.2.1., but also describes the author's experience in some relevant context.

Description of a tool, technique, method, model, etc.: usually highly specific and detailed, as well as technically or methodologically precise.

The Repertory

A Method For The Study of

Cognition in Information Systems.

MIS Quarterly, 26(1), 39-57. Kavan, C. B. (1997). Measuring Information Systems Service Quality: Concerns for a Complete Canvas. MIS Quarterly, 21(2), 209-221.

D. E. (2001). Research

Commentary:

Technology-Mediated

Learning: Call for Greater

Depth and Breadth of

Research. Information

Systems Research,

12(1), 1-10.

Gordon, M. D. and Moore, S. A. (1999)

Depicting the Use and

Purpose of Documents to

Improve Information

Retrieval, Information

Systems Research,

10, 1, 23-37.

Sharda, R., \& Steriger, D. M. (1996). Galletta, D. F., \&

Inductive Model Analysis Systems:

Enhancing Model Analysis in

Decision Support Systems.

Information Systems Research,

7(3), 328-341.
Heckman, R. L. (1990)

A Role Theory Perspective

on End-User Development.

Information Systems

Research, 1(2), 168-187. 


\begin{tabular}{llll}
\hline ID & Category name and description & Example 1 2
\end{tabular}

2 Empirical

2.1 Objects

Descriptions of types or classes of products, None

2.1.2 Descriptions of a specific application,

system, installation, program, etc.

Ahrens, J. D., \& Sankar, C. S. (1993).

Tailoring Database Training for

End Users. MIS Quarterly, 17(4),

419-439.

\subsection{Events/process}

Lab experiment: manipulates independent variable; controls for intervening variables; conducted in controlled settings.

Field experiment: as for lab experiment, but in a natural setting of the phenomenon under study.
Weber, R. (1996). Are Attributes Entities? A Study of Database

Designers' Memory Structures. Information Systems Research, 7(2), 137-162.

Alavi, M., Marakas, G. M., \& Yoo, Y. (2002). A Comparative Study of Distributed Learning Environments on Learning Objects. Information Systems Research, 13(4), 404-415.
Yoo, Y., \& Alavi, M. (2001).

Media and Group

Cohesion: Relative

Influences on Social

Presence, Task Participation, and Group Consensus.

MIS Quarterly, 25(3)

371-390.

Piccoli, G., Ahmad, R.,

\& Ives, B. (2001). Web-based

virtual learning environments:

a research framework and

a preliminary assessment of effectiveness in basic IT skills training. MIS

Quarterly, 25(4), 401-426. 
Table 2 (continued)

\begin{tabular}{|c|c|c|c|}
\hline ID & Category name and description & Example 1 & Example 2 \\
\hline 2.2 .3 & $\begin{array}{l}\text { Field study: No manipulation of independent } \\
\text { variables, involves experimental design but no } \\
\text { experimental controls, is carried out in the } \\
\text { natural settings of the phenomenon of interest. }\end{array}$ & $\begin{array}{l}\text { Barki, H., \& Hartwick, J. (1994). } \\
\text { User Participation, Conflict, and } \\
\text { Conflict Resolution: The Mediating } \\
\text { Roles of Influence. Information } \\
\text { Systems Research, 5(4), 422-438. }\end{array}$ & $\begin{array}{l}\text { Agarwal, R., Sambamruthy, V., } \\
\text { \& Stair, R. M. (2000). } \\
\text { Research Report: The Evolving } \\
\text { Relationship } \\
\text { Between General and Specific } \\
\text { Computer Self-Efficacy? An } \\
\text { Empirical Assessment. } \\
\text { Information Systems Research, } \\
\text { 11(4), 418-430. }\end{array}$ \\
\hline 2.2 .4 & $\begin{array}{l}\text { Positivist case study: investigates one or a } \\
\text { few cases in details from a positivist } \\
\text { perspective, assumes an objective reality } \\
\text { existing independent of humans, may } \\
\text { involve hypothesis testing to discover } \\
\text { the reality. }\end{array}$ & $\begin{array}{l}\text { Yoon, Y., Guimaraes, T., } \\
\text { \& O'Neal, Q. (1995). } \\
\text { Exploring the Factors } \\
\text { Associated } \\
\text { with Expert Systems } \\
\text { Success. MIS Quarterly, } \\
\text { 19(1), 83-106. }\end{array}$ & $\begin{array}{l}\text { Lawrence, M., \& Low, G. (1993). Exploring } \\
\text { Individual User Satisfaction Within User-Led } \\
\text { Development. MIS Quarterly, } \\
\text { 17(2), 195-208. }\end{array}$ \\
\hline 2.2 .5 & $\begin{array}{l}\text { Interpretive case study: studies one or a } \\
\text { few cases from an interpretive perspective, } \\
\text { assumes interactions between researchers } \\
\text { and the phenomenon under investigation, } \\
\text { attempts to understand the phenomenon } \\
\text { through assessing meanings. }\end{array}$ & $\begin{array}{l}\text { George, J. F. (1996). } \\
\text { Computer-Based Monitoring: } \\
\text { Common Perceptions and } \\
\text { Empirical Results. MIS Quarterly, } \\
\text { 20(4), 459-480. }\end{array}$ & $\begin{array}{l}\text { Davidson, E. J. (2002). } \\
\text { Technology frames and } \\
\text { framing: A socio-cognitive } \\
\text { investigation of requirements } \\
\text { determination. MIS } \\
\text { Quarterly, 26(4), 329-358. }\end{array}$ \\
\hline 2.2 .6 & $\begin{array}{l}\text { Survey: Involves large numbers of } \\
\text { observations; the research uses an } \\
\text { experimental design but no controls. }\end{array}$ & $\begin{array}{l}\text { Compeau, D. R., Higgins, C. A., } \\
\text { \& Huff, S. (1999). Social Cognitive } \\
\text { Theory and Individual Reactions } \\
\text { to Computing Technology: } \\
\text { A Longitudinal Study. MIS Quarterly, } \\
\text { 23(2), 145-158. }\end{array}$ & $\begin{array}{l}\text { Chwelos, P., Benbasat, I., } \\
\text { \& Dexter, A. S. (2001). } \\
\text { Research Report: Empirical } \\
\text { Test of an EDI Adoption } \\
\text { Model. Information Systems } \\
\text { Research, 12(3), 304-321. }\end{array}$ \\
\hline
\end{tabular}




\begin{tabular}{|c|c|c|c|}
\hline ID & Category name and description & Example 1 & Example 2 \\
\hline 2.2 .7 & $\begin{array}{l}\text { Development of instruments: description } \\
\text { of development of instrument/measurement } \\
\text { or classification scheme, validation } \\
\text { of instruments. }\end{array}$ & $\begin{array}{l}\text { Agarwal, R., \& Prasad, J. (1998). } \\
\text { A conceptual and operational } \\
\text { definition of Personal Innovativeness } \\
\text { in the domain of information } \\
\text { technology. Information Systems } \\
\text { Research, 9(2), 204-215. }\end{array}$ & $\begin{array}{l}\text { Palmer, J. W. (2002). } \\
\text { Web site usability, design, } \\
\text { and performance metrics. } \\
\text { Information Systems Research, } \\
\text { 13(2), 151-167. }\end{array}$ \\
\hline 2.2 .8 & $\begin{array}{l}\text { Ex-post description of some project or event: } \\
\text { interest in reporting the results of } \\
\text { the project develops after the project is } \\
\text { complete (or is partially complete) }\end{array}$ & None & \\
\hline 2.2 .9 & $\begin{array}{l}\text { Secondary data: Uses data from secondary } \\
\text { sources, i.e., data collected by } \\
\text { sources other than the researchers. }\end{array}$ & $\begin{array}{l}\text { Chin, W. W., \& Newsted, P. R. } \\
\text { (1995). Research Report: The } \\
\text { Importance of Specification in } \\
\text { Causal Modeling: The Case of } \\
\text { End-user Computing Satisfaction. } \\
\text { Information Systems Research, } \\
\text { 6(1), 73-81. }\end{array}$ & $\begin{array}{l}\text { Beath, C. M., \& } \\
\text { Orlikowski, W. J. } \\
\text { (1994). The Contradictory } \\
\text { Structure of Systems } \\
\text { Development Methodologies: } \\
\text { Deconstructing the IS-user } \\
\text { Relationship in Information } \\
\text { Engineering. Information } \\
\text { Systems Research, 5(4), } \\
\text { 350-377 }\end{array}$ \\
\hline 2.2 .10 & $\begin{array}{l}\text { Interview: conducted on an } \\
\text { individual-base. }\end{array}$ & $\begin{array}{l}\text { Straub, D. W. (1994). The Effect } \\
\text { of Culture on IT Diffusion: } \\
\text { E-Mail and FAX in Japan } \\
\text { and the U.S. Information } \\
\text { Systems Research, 5(1), 23-47. }\end{array}$ & $\begin{array}{l}\text { Vandenbosch, B., \& } \\
\text { Higgins, C. (1996). } \\
\text { Information Acquisition and } \\
\text { Mental Models: An } \\
\text { Investigation } \\
\text { into the Relationship Between } \\
\text { Behaviour and Learning,. } \\
\text { Information Systems Research, } \\
7(2), 198-214 .\end{array}$ \\
\hline
\end{tabular}


type if the authors utilized multiple methods. Twenty articles (13\%) utilize two methods while the rest of the articles use only one method.

The inter-rater reliabilities for the entire set of 151 final articles are $64 \%$ for topic and $83 \%$ for type. $70 \%$ is normally an acceptable inter-rater reliability rate. The relatively low agreement for topic has to do with the fact that many papers have multiple topics and only the main topics should be included in the coding. For this complex coding situation (each paper has one to six topics with a mean of 2 and std of 1 , compared to normal situations where each paper has one code), we believe that $64 \%$ agreement rate is reasonable. The number of papers with any disagreement is 61. All disagreement was resolved after discussions. Average independent coding time is 14 minutes per paper per coder. Average time for resolving disagreement is eight minutes per paper.

\section{Results}

\subsection{Topic}

Table 3 shows the frequencies and percentages of articles on research topics. Fig. 6 summarizes the article numbers into the three sub-areas.

Among this collection of papers, the dominating studies are on IS/IT use, evaluation and impact ( $82 \%$ of the overall topics). $14 \%$ of the topics fall in the sub-area of IS/IT development. Only 3\% of the subject topics address general research-related issues such as methodology and measurement concerns, while no article involves education such as curriculum or study programs.

The number of studies in the IS/IT use, evaluation and impact sub-area also shows an increasing trend over the years. As shown in Table 3, the most studied topic is behavioral, including studies pertaining to perception, belief, intention, behavior, acceptance, adoption, use, resistance to use, and continued use. The topic on attitude, satisfaction, and preference follows, which is followed by the topic on performance and productivity.

The sub-area of IS/IT development takes only 14\% of the collection. Among this sub-area, the most interest has been on user analyst involvement, followed by software/hardware development. User interface design, development and evaluation studies are covered only 13 out of 46 papers of this sub-area.

Overall, the results on the research topic indicate that this collection of research emphasizes a great deal on issues that occur during the stage where IS/IT artifacts have already been released and in use.

\subsection{Type/method}

The frequencies and percentages of research methods utilized in the articles are shown in Table 4 and Fig. 7.

Overall, the frequency of empirical methods $(83 \%)$ dramatically exceeds that of non-empirical ones $(17 \%)$. The frequency of non-empirical studies has been fairly 
Table 3

Results on research topic

\begin{tabular}{|c|c|c|c|c|c|c|c|c|c|c|c|c|c|c|c|}
\hline Topic & 90 & 91 & 92 & 93 & 94 & 95 & 96 & 97 & 98 & 99 & 00 & 01 & 02 & Total & $\%$ \\
\hline IS/IT development & 5 & 4 & 5 & 4 & 6 & 3 & 5 & 2 & 2 & 3 & 2 & 1 & 4 & 46 & 14.3 \\
\hline Development methods and tools & & & & & 1 & & & & & & & & & 1 & 0.3 \\
\hline User analyst involvement & 2 & & & 1 & 4 & & 1 & 1 & 1 & & & 1 & 2 & 13 & 4.2 \\
\hline Software/hardware development & 1 & 2 & & 1 & & 1 & 3 & 1 & & 1 & & & & 10 & 3.3 \\
\hline Software/hardware evaluation & & & & & & & & & 1 & & & & & 1 & 0.3 \\
\hline User interface design \& development & 1 & 2 & 1 & & & 1 & & & & 1 & 1 & & & 7 & 2.3 \\
\hline Interface evaluation & & & 1 & & & 1 & & & & 1 & 1 & & 2 & 6 & 2.0 \\
\hline User training & & & 2 & 2 & 1 & & 1 & & & & & & & 6 & 2.0 \\
\hline IS/IT use, evaluation, impact & 15 & 13 & 15 & 14 & 12 & 19 & 17 & 12 & 25 & 25 & 32 & 23 & 29 & 251 & 82.4 \\
\hline Behavior & 5 & 7 & 4 & 5 & 4 & 7 & 3 & 5 & 7 & 8 & 12 & 7 & 11 & 85 & 27.7 \\
\hline Attitude & 4 & 3 & 1 & 3 & 3 & 6 & 3 & 1 & 3 & 5 & 1 & 3 & 5 & 41 & 13.4 \\
\hline Learning & & & 1 & 1 & 2 & 1 & 2 & 1 & & 3 & 1 & 2 & 1 & 15 & 4.9 \\
\hline Motivation & & & & & & 1 & 1 & 1 & 2 & 1 & 2 & 1 & 1 & 10 & 3.3 \\
\hline Emotion & & 1 & 1 & & & 1 & & & 2 & 1 & 3 & 2 & 3 & 14 & 4.6 \\
\hline Performance & 3 & 2 & 3 & 3 & 1 & 2 & 4 & 2 & 4 & 2 & 6 & 5 & 1 & 38 & 12.4 \\
\hline Trust & & & & 1 & & & 1 & & 1 & & & & 3 & 6 & 2.0 \\
\hline Ethics & & & & & & & 1 & & 1 & 2 & & & & 4 & 1.3 \\
\hline Individual differences & 1 & & 5 & 1 & 1 & & 2 & 1 & 4 & & 2 & 1 & 2 & 20 & 6.5 \\
\hline Individual demographics & 1 & & & & & 1 & & 1 & 1 & 1 & 4 & & 1 & 10 & 3.3 \\
\hline Interpersonal relationship & 1 & & & & 1 & & & & & 2 & 1 & 2 & 1 & 8 & 2.6 \\
\hline User support & 1 & & 1 & & & & & & & & & & & 2 & 0.7 \\
\hline Research \& education & & & & 1 & & 2 & & 3 & 1 & 1 & & 1 & 1 & 10 & 3.3 \\
\hline Research & & & & 1 & & 2 & & 3 & 1 & 1 & & 1 & 1 & 10 & 3.3 \\
\hline Education & & & & & & & & & & & & & & & 0.0 \\
\hline Total & 20 & 17 & 20 & 19 & 18 & 24 & 22 & 17 & 28 & 29 & 34 & 25 & 34 & 307 & 100 \\
\hline
\end{tabular}

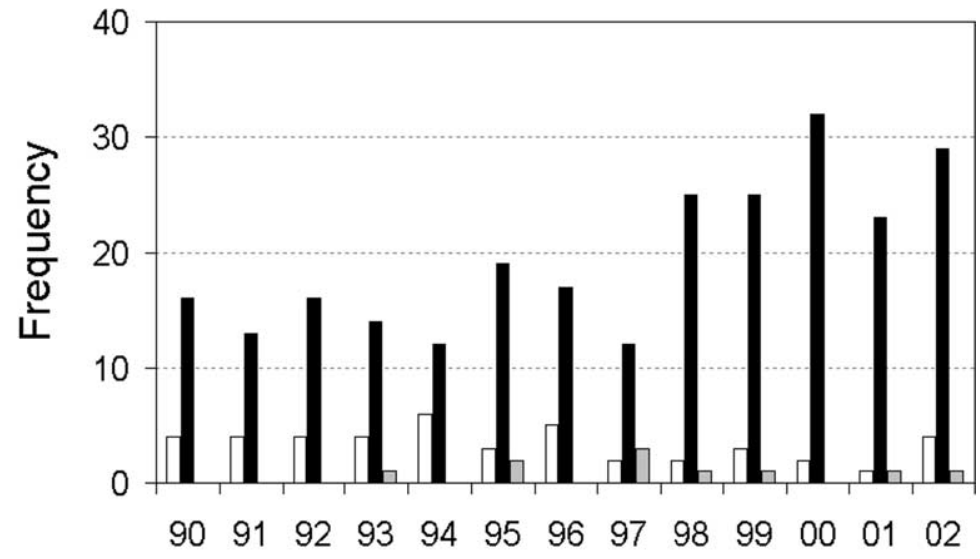

$\square$ IS/IT development $\square$ IS/IT use, evaluation, impact $\square$ Research \& education

Fig. 6. Results on research topic: sub-areas. 
Table 4

Results on research type

\begin{tabular}{|c|c|c|c|c|c|c|c|c|c|c|c|c|}
\hline Type & & 91 & 19293 & 394 & 959 & 69 & 979 & 89 & 9900 & 0010 & 02 Tota & $1 \%$ \\
\hline Non-Empirical & 4 & 3 & 31 & 10 & 2 & 2 & 3 & 3 & 30 & 03 & 229 & 17.0 \\
\hline Conceptual orientation & 1 & 1 & & & & 1 & & 2 & 1 & 1 & 7 & 4.1 \\
\hline Frameworks & & & & & & & & & & & & 0.0 \\
\hline Conceptual model & 1 & & & & & 1 & & 2 & 1 & 1 & 6 & 3.5 \\
\hline Conceptual overview & & 1 & & & & & & & & & 1 & 0.6 \\
\hline Theory from reference disciplines & & & & & & & & & & & & 0.0 \\
\hline Illustrative & 1 & 1 & 31 & & 1 & & 3 & 1 & 1 & 1 & 114 & 8.2 \\
\hline Opinion with examples & 1 & 1 & 31 & & 1 & & 3 & 1 & & 1 & 12 & 7.0 \\
\hline Opinion with personal experiences & & & & & & & & & & & & 0.0 \\
\hline Description of tools, techniques & & & & & & & & & 1 & & 12 & 1.2 \\
\hline Applied concepts & 2 & & & & 1 & & & & 1 & 1 & 18 & 4.7 \\
\hline Applied concepts & 2 & 1 & & & 1 & 1 & & & 1 & 1 & 18 & 4.7 \\
\hline Empirical & 5 & 6 & 911 & 114 & 131 & & 8 & & 1312 & 2131 & 17142 & 83.0 \\
\hline Objects & & & 1 & 1 & & & & & & & 1 & 0.6 \\
\hline Description of types/classes of products, technologies, etc & & & & & & & & & & & 0. & \\
\hline Description of specific applications, systems, etc. & & & 1 & 1 & & & & & & & 1 & 0.6 \\
\hline Events/Processes & 5 & 6 & 910 & 014 & 131 & & 8 & & 1312 & 2131 & 17141 & 82.5 \\
\hline Lab experiment & 1 & 2 & 44 & 42 & 3 & 3 & 3 & & 67 & 73 & 343 & 25.1 \\
\hline Field experiment & 1 & & & 2 & & 2 & 1 & & & 1 & 29 & 5.3 \\
\hline Field study & 2 & 1 & & 1 & 1 & & 2 & & 32 & 2 & 315 & 8.8 \\
\hline Positivist case & & & 1 & 1 & 1 & & & 2 & & & 4 & 2.3 \\
\hline Interpretive case & 1 & & 1 & & & 1 & & 2 & & 1 & 17 & 4.1 \\
\hline Survey & & 2 & 33 & 35 & 5 & 4 & 2 & 2 & 32 & 27 & 543 & 25.1 \\
\hline Develop of instrument & & 1 & 1 & 1 & & 1 & & 1 & 1 & & 39 & 5.3 \\
\hline Secondary data & & & & 11 & 2 & & & & & 1 & 5 & 2.9 \\
\hline Interview (individual based) & & & & 12 & 1 & 1 & & & & 1 & 6 & 3.5 \\
\hline Total & 9 & 9 & 1212 & 214 & & & & & & & 19171 & 100.0 \\
\hline
\end{tabular}

stable over the years. Among them, opinion with examples, applied concepts, and conceptual models have been fairly utilized.

Empirical studies have been conducted almost entirely on events/processes (versus on objects). In particular, lab controlled experiment and survey method, each counting about $25 \%$ of all the methods utilized, dominate the collection. They are followed by field study, field experiment, development of instrument, interpretive case study, secondary data, interview, and positivist case study.

It is notable that four methods (Framework, Theory from reference disciplines, Opinion with personal experience, and Description of types/classes of products) have not been utilized in this collection of papers.

\subsection{Publication patterns}

In order to demonstrate the publication rates and trends of HCI studies in the two journals, the total number of published research articles is counted. Fig. 8 depicts the publication patterns of HCI studies in the two journals, and as a whole. 


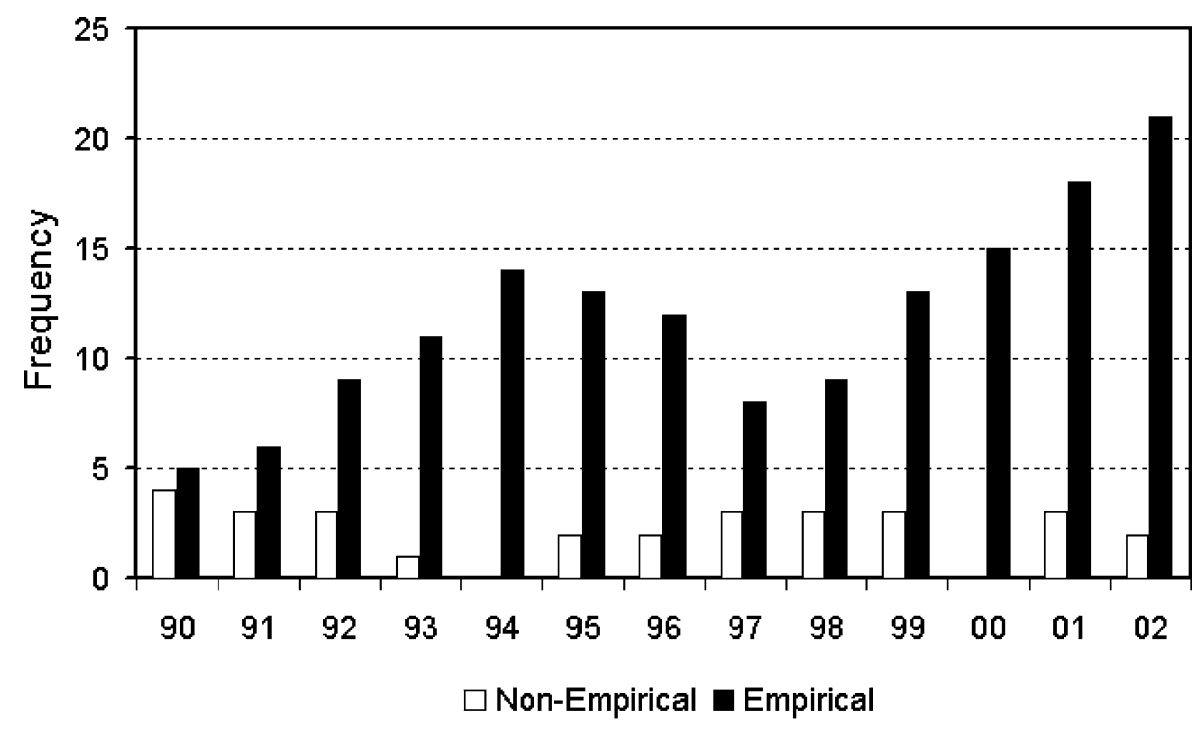

Fig. 7. Results on research type: frequency of articles by methodology.

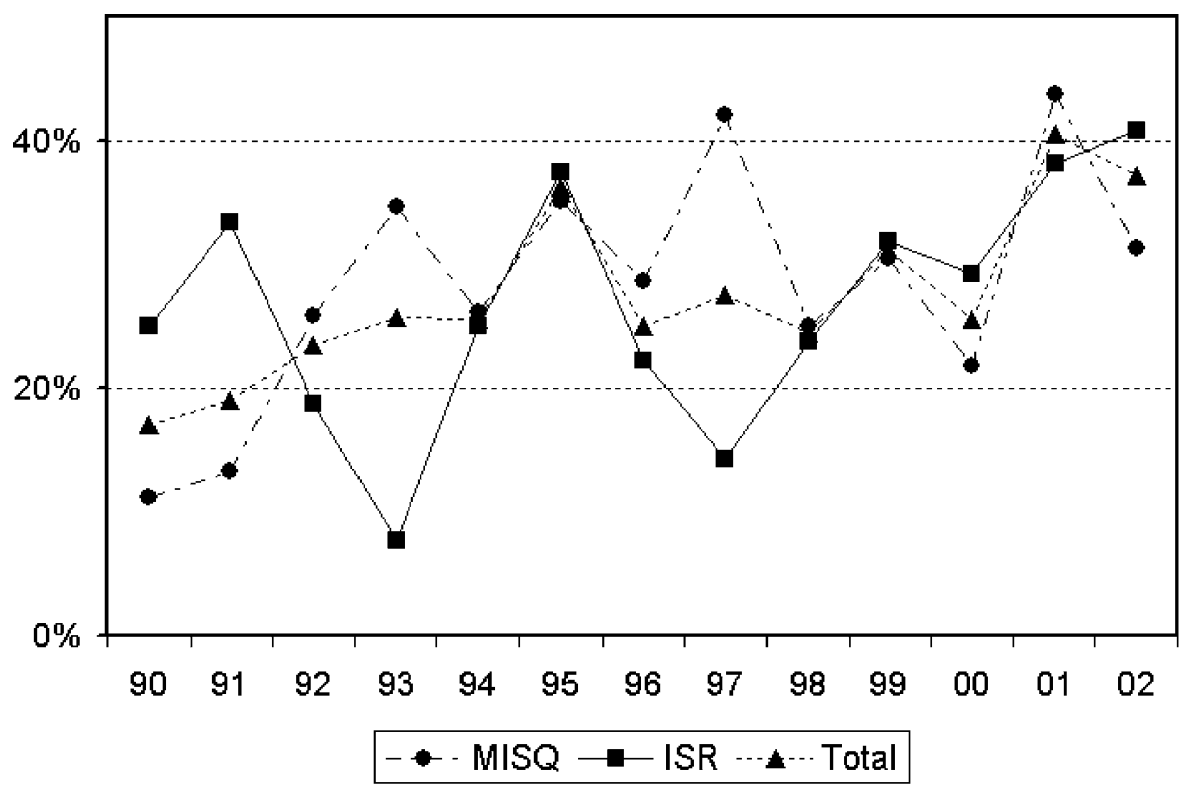

Fig. 8. Publication patterns.

It shows that there is an increasing trend of percentage of HCI studies in the two journals over the years. The overall percentage of HCI studies is around $40 \%$ of all published articles in these two journals during recent years. This is an encouraging discovery for scholars conducting research in this subfield. 


\section{Discussion and conclusion}

By examining existing HCI frameworks, proposing a new one to address the broad HCI issues and concerns, and assessing published articles, this paper contributes to our understanding of the current status of research topics, methods, and publication patterns of the HCI studies in the MIS discipline. This understanding is important for the identification and promotion of this emerging subfield in MIS. It should of interest to researchers and young scholars for their future research, collaboration, and publication.

This paper is the first attempt to draw such an understanding of HCI studies in MIS based on the evidence of published articles. As such it is limited in scope due to the time consuming nature of such studies. In order to provide an informative picture, only the most recent 13 years of the two top MIS journals are selected as paper sources. Although the 13-year time period is reasonable for this type of research assessment, the journal selection may have had a strong influence on the assessment results. This includes the potential biases of the two journals' emphases on publishable topics and methods. The HCI type research publication pattern may also be affected by the two journals' characteristics.

Another limitation of the paper is the omission of other possible aspects for assessment. For example, the assessment of research can also include active researchers and institutions as some of the MIS research assessment articles did (Pervan, 1998; Romano \& Fjermestad, 2001). This can provide useful information for young scholars or doctoral students to identify potential academic homes where collaboration is highly possible, and their research interests and effort can be recognized and appreciated. We decided to omit this assessment in this paper as we realized that limiting such a study to two journals might provide a skewed picture.

Future research is planned to include relevant papers in more major MIS journals, and to provide additional assessments such as specific technologies studied, contexts where studies are conducted, and active researchers and institutions.

The fast development and pervasive use of technology prompt a need to reexamine the broad HCI issues in light of the IS/IT development, actual use, and impact on all aspects of our lives. The new framework proposed in this paper emphasizes the entire interaction cycle between humans and technology, rather than a stage or part of it. It also brings in the tasks and contextual factors. This view is intended to show the dynamic as well as the evolutional aspect of issues and concerns regarding the interactions between humans and technology.

The assessment of a limited collection of HCI studies in two top MIS journals demonstrates a wide range of research issues and topics being studied by MIS researchers over the past thirteen years. The dominating issues fall in the area of IS/ IT use, evaluation and impact. MIS researchers are more concerned with issues that occur after IS/IT is developed. These concerns are closely related to humans' perceptions, beliefs, behavior, attitude, satisfaction, performance and productivity, and individual differences. Among the small percentage of studies focusing on the development stage, MIS researchers are concerned with user involvement and 
participation, user-analyst differences and interaction, programmer cognition studies, and design methods.

The assessment also shows a broad range of research methods employed. The dominating methods, however, lie in empirical studies utilizing lab experiments and surveys to examine issues on events and processes. Due to the dynamic nature of human interaction with technology, task, and context, it may indicate a need to utilize more interpretive research methods such as phenomenology, action research, ethnography, grounded theory, etc. It would help advance the subfield more if there are general instruments being developed and validated, rather than many researchers reinventing the wheel. There are few studies focusing on providing frameworks and high-level overviews of the subfields, which indicates potential research efforts in the future.

Overall, it is exciting to see that there is an increasing number and percentage of HCI studies published in the two top MIS journals over the years. The current status of the subfield may indicate an emerging state, rather than a mature one.

\section{Acknowledgements}

The authors thank the guest editor, Dr. Henry H. Emurian, and two anonymous reviewers for their helpful comments and suggestions on an earlier version of the paper.

\section{References}

Alavi, M., \& Carlson, P. (1992). A review of MIS research and disciplinary development. Journal of Management Information Systems, 8(4), 45-62.

Barki, H., Rivard, S., \& Talbot, J. (1988). An information systems keyword classification scheme. MIS Quarterly, 12(2), 299-322.

Barki, H., Rivard, S., \& Talbot, J. (1993). A keyword classification scheme for IS research literature: an update. MIS Quarterly, 17(2), 209-266.

Baskerville, R. L., \& Myers, M. D. (2002). Information systems as a reference discipline. MIS Quarterly, 26(1), 1-14.

Carroll, J., Kellogg, W., \& Rosson, M. B. (1991). The task-artifact cycle. In J. Carroll (Ed.), Designing interaction (pp. 74-102). Cambridge University Press.

Compeau, D. R., Higgins, C. A., \& Huff, S. L. (1999). Social cognitive theory and individual reactions to computing technology: a longitudinal study. MIS Quarterly, 23(2), 145-158.

Culnan, M. J. (1987). Mapping the intellectual structure of MIS, 1980-1985: a co-citation analysis. MIS Quarterly, 11(3), 341-353.

Davis, F. (1989). Perceived usefulness, perceived ease of use, and user acceptance of information technology. MIS Quarterly, 13(3), 319-340.

Eason, K. D. (1991). Ergonomic perspective on advances in human-computer interaction. Ergonomics, 34(6), 721-741.

Goodhue, D. L. (1997). The model underlying the measurement of the impacts of the IIC on the end-users. Journal of the American Society for Information Science, 48(5), 449-453.

Goodhue, D. L. (1998). Development and measurement validity of a task-technology fit instrument for user evaluations of information systems. Decision Sciences, 29(1), 105-137. 
Goodhue, D. L., \& Thompson, R. L. (1995). Task-technology fit and individual performance. MIS Quarterly, 19(2), 213-236.

Hewett, T., Baecker, R., Card, S., Carey, T., Gasen, J., Mantei, M., Perlman, G., Strong, G., \& Verplank, W. (1992). ACM SIHCHI curricula for human-computer interaction. Association for computing machinery. New York, NY: ACM.

Lucas, H. C. (1975). Performance and the use of an information system. Management Science, 21(8), 908919.

Pervan, G. P. (1998). A review of research in Group Support Systems: leaders, approaches and directions. Decision Support Systems, 23, 149-159.

Preece, J., Rogers, Y., Sharp, H., Benyon, D., Holland, S., \& Carey, T. (1994). Human-computer interaction. Addison-Wesley.

Romano, N. C., \& Fjermestad, J. (2001). Electronic commerce customer relationship management: an assessment of research. International Journal of Electronic Commerce, 6(2), 61-113.

Swanson, E. B. (1974). Management information systems: appreciation and involvement. Management Science, 21(2), 178-188.

Venkatesh, V., \& Davis, F. (2000). A theoretical extension of the technology acceptance model: four longitudinal field studies. Management Science, 46(2), 186-204.

Zhang, P., Benbasat, I., Carey, J., Davis, F., Galletta, D., \& Strong, D. (2002). Human-computer interaction research in the MIS discipline. Communications of the AIS, 9(20), 334-355.

Zhang, P., \& Dillon, A. (2003). HCI and MIS: Shared Concerns, Editorial Introduction. International Journal of Human-Computer Studies, 59(4), 397-402. 